\title{
Crecimiento económico de las cajas de comunidad en la jurisdicción de Otumba, siglo XVIII
}

Economic Growth of the Community Coffers in the Jurisdiction of Otumba in the Eighteenth Century

edgar mendoza garcía. Doctor en Historia por El Colegio de México, investigador del CIESAS, Sede Ciudad de México. Miembro del SNI nivel II, sus líneas de investigación se centran en la historia social, política y agraria en el ámbito regional del siglo XVIII al XX. Es autor del libro, Agua y tierra en San Gabriel Chilac Puebla y San Juan Teotibuacán, Estado de México. El impacto de la reforma agraria sobre el gobierno local, 1917-1960, CIESAS, 2016.

RESUMEN. El objetivo de este artículo es examinar cómo se manifestó el crecimiento de las propiedades de las cajas de comunidad de los pueblos de indios de la jurisdicción de Otumba en la Intendencia de México durante el siglo XVIII, explicar las consecuencias de las reformas borbónicas sobre la organización y funcionamiento de esta institución económica, señalar algunas prácticas de defensa de los actores sociales ante el establecimiento de Reglamentos específicos que afectaban sus costumbres y disminuían los gastos en sus fiestas religiosas, y en suma, para transferir los excedentes comunales hacia las arcas reales, restar el poder y la autonomía política y económica de la república de indios y los líderes locales.

PALABRAS CLAVE. Indios, cajas de comunidad, tierras, economía, reformas borbónicas

ABSTRACT. The aim of this article is to consider how the growth of the properties of community coffers of Indian villages from the jurisdiction of Otumba were manifest in the colonial Intendancy of Mexico during the Eighteenth Century, and to explain the consequences of the Bourbon Reforms on the organization and functioning of this economic institution, point out some practical defense strategies of social actors against the establishment of specific regulations that affected their customs and reduced spending on their religious holidays, and in sum, transferred the community surplus into the royal coffers and reduced the power and political and economic autonomy of the republic of Indians and local leaders.

KEYWORDS. Indians, community coffers, lands, economy, Bourbon Reforms

INFORMACIÓN DEL ARTÍCULO

Recibido: 8 de junio de 2017

Aprobado: 9 de febrero de 2018

Correo para correspondencia: emgarcia@ciesas.edu.mx / edgarmengar@hotmail.com 


\section{Crecimiento económico de las cajas de comunidad en la jurisdicción de Otumba, siglo XVIIIedgar mendoza garcía}

INTRODUCCIÓN

Lejos quedó aquella imagen de los pueblos de indios marginados y cerrados a las dinámicas del mercado. ${ }^{1}$ Por el contrario, los estudios regionales de las últimas décadas ilustran la participación de la producción india en los circuitos mercantiles de la Nueva España y de otras latitudes del imperio español. ${ }^{2}$ Del mismo modo, quedo superada aquella visión historiográfica que sustentaba que la segunda mitad del siglo XVIII, fue de desarrollo general en la producción minera y otras actividades pecuniarias. Hoy se sabe que el crecimiento económico se inició desde la primera mitad de dicho siglo y que durante la segunda parte, también hubo ciclos de estancamiento en ciertos sectores de la economía, incluso en la minería. ${ }^{3}$

Aunque la política económica emprendida por los borbones tenía el fin de ejercer un mayor control sobre la administración pública para obtener más ingresos fiscales y aumentar el rendimiento de las principales actividades económicas de sus colonias. Algunas ideas para llevar a cabo dichos propósitos ya se perciben en la legislación anterior. Una muestra de ello es la que se refiere a las cajas de comunidad de los pueblos de indios de la Recopilación de Leyes de los Reinos de Indias de 1680. Desde entonces se especificaron disposiciones que intentaban restar el poder y la autonomía de estas corporaciones. Por ejemplo, se reglamentó la administración de las cajas de comunidad y se trató

1 Wolf, (1957).

2 Ortelli (2011); Escobar y Gayol (2012).

3 Randall (1977); Coatsworth (1990); Marichal (2012). 
de limitar sus acciones para proteger y acrecentar los bienes económicos de los pueblos y hacerlos disponibles como préstamos o censos. ${ }^{4}$

Pero a pesar de la creación de un aparato judicial y administrativo que intentaba regularlos, y de la vigilancia que ejercieron las autoridades para que únicamente cubrieran sus necesidades tributarias y de ayuda mutua, los pueblos de indios y sus gobernadores continuaron administrando sus recursos comunales y utilizando los ingresos en obras públicas y fiestas religiosas. ${ }^{5}$ Sin embargo, esta autonomía relativa, sufrió cambios notables con la llegada de José de Gálvez quién en 1765 dictó una Instrucción para el arreglo de las cajas de comunidad, que más adelante se concretarían en la Contaduría de Propios, Arbitrios y Bienes de Comunidad, y principalmente cuando se promulgó la Ordenanza de Intendentes y se reforzó el sistema administrativo sobre las cajas de comunidad. A diferencia de la Recopilación de 1680, la Ordenanza de Intendentes de 1786 logró impulsar la mayor parte de sus objetivos. De modo que, durante las últimas décadas del siglo XVIII, se prohibieron los gastos excesivos en las festividades religiosas, se ordenó arrendar las tierras sobrantes y el excedente de las cajas de comunidad se transfirió para su supuesto resguardo a las cajas reales. ${ }^{6}$

El presente artículo tiene el propósito de analizar los factores que permitieron el crecimiento de los bienes y las cajas de comunidad y su vinculación con el mercado regional en la jurisdicción de Otumba, de la Intendencia de México. Asimismo, intenta dilucidar cuál fue el impacto y la actitud de los pueblos de indios ante las reformas administrativas de fines del siglo XVIII. ¿ Se puede hablar de un incremento económico interno en los pueblos de indios o de deterioro? ¿Quiénes fueron los sectores afectados y beneficiados en dicho proceso?

Antes de continuar, cabe aclarar que los términos bienes de comunidad y cajas de comunidad, no significan lo mismo, si bien algunos historiadores señalaron hace tiempo que éstos se emplearon como sinónimos a lo largo del

\footnotetext{
4 Lira (1980).

5 Lamas (1957).

6 Menegus (1989, p. 385).
} 
periodo colonial, y que ambos hacían referencia a dos partes de la hacienda de los pueblos de indios. ${ }^{7}$ García Martínez aclara que el concepto de "comunidad", estaba asociado al patrimonio colectivo, "los bienes del común”, es decir al régimen económico de los pueblos de indios. ${ }^{8}$ En el presente estudio se hace una distinción: por bienes de comunidad entendemos todos aquellos recursos colectivos que poseían los pueblos de indios, ${ }^{9}$ en cambio, las cajas de comunidad eran el receptáculo donde se guardaban no sólo los títulos primordiales sino también los libros de ingresos y egresos, así como el dinero y otros artículos importantes. Las cajas de comunidad eran cofres con tres llaves, una a cargo del gobernador, otra en manos del cura y una más en poder del corregidor o del alcalde mayor, aunque esto vario según las regiones y a través del tiempo. ${ }^{10}$

PUEBLOS DE INDIOS Y ECONOMÍA

Varios historiadores han dado cuenta de la participación de los pueblos de indios en el mercado novohispano, pero la mayor parte de los estudios sobre la economía india del siglo XVIII sustentan sus argumentaciones a partir de dos rubros; en primer lugar se distinguen los que analizan el repartimiento de mercancías, ${ }^{11}$ y los que han utilizado como fuente principal las alcabalas y el Cuaderno de Indios de $1792,{ }^{12}$ y en segundo, los que abordan a las cofradías no solo como instituciones de ayuda mutua o sistema de cargos cívico religio-

7 Casa, Zavala et al. (1952, p. 89); Lamas (1957, p. 298); Nava (1971).

8 García Martínez (2005, p. 102).

9 Según la región, los pueblos poseían diversas tierras de cultivo, ranchos, haciendas, casas, mesones, trapiches, pastos, lagunas, manantiales, trajineras, salinas, ganado menor y mayor, molinos de trigo, nopales de grana, magueyes, pulque, mezcal, etc.

10 Dehouve (2001, p. 104); Lamas (1957); Caso, Zavala et al. (1954, p. 89); García Martínez (2005, pp. 104-105).

11 Pietschmann (1988); Graso (1999); Garavaglia y Grasso (1987); Carmagnani (1988); Hamnett (1976); Ouweneel (2000); Arrioja (2011); Baskes (1996); Machuca (2012).

12 Silva (1994); Navarrete (2012); Ramírez (2012); Fagoaga (2004). 
so sino también como espacios de crédito y actividad comercial, ${ }^{13}$ pero a mi juicio, han dejado al margen la producción colectiva, es decir, los bienes de comunidad que también ingresaban al mercado.

La importancia de las cajas y los bienes de comunidad, se vislumbran en varias obras, donde incluso, se han definido los conceptos, pero no se ha profundizado en su ámbito económico. ${ }^{14}$ Existen estudios regionales y locales que han abordado esta institución en diferentes periodos y bajo distintos enfoques. En 1957 Adolfo Lamas, a partir del sistema de propiedad agraria y la legislación indiana cuestionó el origen de las cajas de comunidad y sus finalidades, señalando que si bien, éstas tenían antecedentes prehispánicos, también se combinaron y adaptaron con elementos hispánicos, para finalmente adquirir un carácter propio, tanto novohispano como mexicano. ${ }^{15}$ En este artículo pionero, Lamas aborda de manera general los cambios legislativos y ciertas transformaciones de esta institución desde el siglo XVI hasta fines del siglo XVIII.

Asimismo, existen dos libros que tratan en específico los bienes y cajas de comunidad; el primero de Lara Tenorio, analiza las cuentas y formas de financiamiento de la caja de comunidad de Tehuacán Puebla desde fines del siglo XVI a principio del XVII. ${ }^{16}$ Por su parte, Mendoza, examina la persistencia de los bienes de comunidad en ciertos pueblos y municipios de la Mixteca alta durante el siglo XIX, que se resistieron o adaptaron a las reformas liberales. ${ }^{17}$ En la misma línea se ubica la tesis de Diana Birrichaga, quien a partir de la legislación no solo describe el tránsito de los bienes de comunidad a los propios de la municipalidad republicana en los pueblos de Texcoco, sino también da cuenta de su administración, funcionamiento y conflictos entre pueblos y municipalidades. ${ }^{18}$

13 Carrera, Cruz, et al., (2010); Martínez y Von Woobeser, et al., (1998); Dehouve, (1988); Palomo, (2009); Lavrin, (1998); Bechtloff, (1996); Solís, (2003), Mendoza, (2011); Cruz, (2011).

14 Caso, Zavala, et al, (1954); Dehouve, (2001); García (2005); Lira (1980, 1995); Tanck (1999).

15 Lamas (1957).

16 Lara (2005).

17 Mendoza (2004 y 2011).

18 Birrichaga (2003). 
En otra temporalidad, un puñado de historiadores ha centrado su atención en la segunda mitad del siglo XVIII, observando el impacto de las reformas borbónicas sobre distintos aspectos que afectaron la organización y funcionamiento de los bienes y cajas de comunidad de los pueblos de indios. Por ejemplo, Dorothy Tanck, a partir de los reglamentos indagó la relación entre cajas de comunidad y la fundación de escuelas en Yucatán. ${ }^{19}$ Asimismo, Marta Terán al igual que Marín y Cedeño, con base en las finanzas, señalaron la pérdida de autonomía y los conflictos que se suscitaron en algunos pueblos de Michoacán. ${ }^{20}$ En cambio, Bustamente mostró que las reformas sobre los bienes y cajas de comunidad no se aplicaron en la provincia de Tlaxcala, donde el cabildo defendió sus antiguos privilegios. ${ }^{21}$

Por su parte, Margarita Menegus, ha tratado con detalle la legislación sobre las cajas de comunidad y al mismo tiempo, ha reflexionado sobre contribuciones, inversión, reglamentos y el impacto de las reformas borbónicas para impulsar la monetarización de la economía de los pueblos de indios. ${ }^{22}$ En otro texto innovador por su enfoque comparativo, la misma autora da cuenta de los cambios en la propiedad de la tierra y el aumento del caudal de las cajas de comunidad a fines del siglo XVIII en distintos pueblos de Toluca, Guadalajara y Zacatecas. ${ }^{23}$ Sin embargo, el camino trazado por Menegus ha tenido pocos seguidores. Así qué desde esta óptica, trataremos de reflexionar sobre el crecimiento económico de los pueblos de indios de Otumba a partir de sus bienes y cajas de comunidad.

Cabe señalar, que sobre este espacio, ya existe el estudio de Guadalupe Nava sobre los pueblos de Otumba y Teotihuacán, y aunque de forma general revela varios casos de "la mala administración de las cajas de comunidad", y señala los desfalcos y procesos en contra de ciertos gobernadores en la segunda mitad del siglo XVIII y primeros años del siglo XIX, no percibe las coyunturas históricas, ni analiza los cambios que provocaron las reformas borbónicas y

19 Tanck (1994).

20 Terán (2003); Cedeño (2003); Marín (2013).

21 Bustamante $(2010)$.

22 Menegus (1988; 1989; 1995).

23 Menegus (1999). 
los reglamentos que se hicieron sobre estas instituciones. ${ }^{24}$ Asimismo, incluyó a los pueblos de Otumba bajo la jurisdicción de San Juan Teotihuacán, cuando desde principios del siglo XVIII ya existía la Alcaldía mayor de Otumba, la cual se convirtió en Subdelegación con la creación de las intendencias en $1786 .{ }^{25}$

A diferencia de los estudios anteriores, el presente abarca desde la Recopilación de leyes y reinos de indias de 1680, es decir, cuando por primera vez la Corona intentó regular la administración de las cajas de comunidad, hasta la llegada de Gálvez en 1765 y el establecimiento de reglamentos específicos para cada pueblo durante las últimas décadas del siglo XVIII, al mismo tiempo, a partir de cuatro series de cuentas completas de los pueblos de Otumba (1705, 1778,1794 y 1806) y otros documentos primarios, se corrobora con datos cuantitativos el crecimiento económico de los bienes de las cajas de comunidad y se confirman las hipótesis de Margarita Menegus y otros estudiosos de la época. También se analizan algunos casos de corrupción de los gobernadores de los pueblos de indios, un tema poco tratado hasta ahora por la historiografía, lo que coadyuva a comprender la estratificación social de los pueblos, así como los intereses y pugnas entre las élites locales por el control y la administración de los bienes colectivos.

A mi juicio, las cajas de comunidad no sólo fueron un sistema de ahorro comunitario, sino también una empresa comunal, un mecanismo de comercialización y de integración de los pueblos de indios al mercado colonial, así como de socialización con otros grupos sociales. ${ }^{26} \mathrm{El}$ pueblo de indios fue al mismo tiempo productor de bienes agropecuarios y consumidor de artículos y mercancías ya fueran novohispanas o peninsulares. Además porque para este periodo, necesitaban dinero para pagar el tributo, financiar los gastos del culto religioso, solventar los litigios por tierras en contra de otros pueblos rivales y particulares, lo que obligó a los indios no sólo a vender su fuerza de trabajo,

24 Nava (1971). Por ejemplo, esta autora usa indistintamente los términos, comunidad indígena, pueblos de indios, sobre esta discusión, véase García Martínez (2005); Lira (1980); Tanck (1999).

25 Véase el Reglamento sobre los bienes de comunidad de los pueblos de la jurisdicción de San Juan Teotihuacán, AGN, Indios, vol. 79, exp. 6, fs125-154, año de 1806.

26 Mendoza (2002, 2004). 
sino también a comercializar sus productos y participar en el mercado. ${ }^{27} \mathrm{Mu}$ chos individuos se involucraban en las actividades comerciales para obtener unas monedas y cubrir sus contribuciones, ${ }^{28}$ por ejemplo, un natural del pueblo de Cuautlancingo se quejó porque el teniente del alcalde mayor de Otumba, le había quitado el dinero de su venta de pulque, y según relató, ese dinero le servía para pagar los reales tributos y mantener a su familia. ${ }^{29}$

En suma, la integración del indio a la economía colonial se dio por dos vías; como unidad corporativa y de manera individual, y reflejan el proceso de individualización económica y social. Parafraseando a Felipe Castro, los indios estuvieron integrados a la vida económica colonial, ya fuera como trabajadores, consumidores de mercancías o como contribuyentes fiscales. ${ }^{30}$ En esta ocasión me limitaré a observar de forma general la producción colectiva, dejando a un lado la participación de los grupos domésticos.

Por el momento solo contamos con tres registros seriados de las cuentas de comunidad de la jurisdicción de Otumba a lo largo del siglo XVIII, que indican las condiciones económicas de los pueblos de indios. El primero, es un informe elaborado por el alcalde mayor en 1705 de los bienes de comunidad de los cuatro pueblos de Otumba, (Ostoctipac, Cuautlancingo, Axapusco y Otumba), ${ }^{31}$ el segundo, es la aplicación del reglamento y sus consecuencias inmediatas entre 1778 y $1784,,^{32}$ y el tercero lo constituye una fuente de 1794

27 Pietschmann (1988, p. 124); Van Young (1989); Dehouve (2001); Menegus (1999); Arrioja (2011). Sin embargo, hay historiadores que señalan la escasez de circulante en las transacciones menudas y la presencia del trueque en las sociedades rurales durante el periodo colonial. Véase Romano (1998) y Céspedes (1996). No obstante, considero que a fines del siglo XVIII hubo una mayor monetarización de la economía indígena, sobre todo en las regiones más dinámicas que se vincularon al mercado regional e internacional.

28 Castro (2010, pp. 97-100); Marichal (2012, pp. 107-109).

29 AGN, Indios, vol. 33, exp, 198, fs, 143-143v.

30 Castro (2010, p. 108).

31 AGN, Indios, vol. 97, fs. 326-329. Año 1705.

32 AGN, Tierras, vol. 3048, exp. 2, fojas 50-152, (1778-1779), Don Pedro Joseph de León, alcalde mayor, hace Pregón sobre tierras de comunidad de Otumba: AGN, Tierras, 3048, exp. 2, fs. 71-73. (año 1784). 
que describen la situación de las cajas de comunidad de los mismos pueblos. ${ }^{33}$ A través del análisis de estos y otros documentos complementarios, como el reglamento de $1806,{ }^{34}$ se puede detectar el crecimiento de los bienes de comunidad durante el siglo XVIII, observar la política del imperio español sobre cajas de comunidad, conocer la organización política y económica de los pueblos para administrar sus bienes y articular la producción local con el mercado regional, y finalmente para estar al tanto de los conflictos internos y externos que se gestaron en este proceso. Así, como hipótesis trataré de subrayar que la economía de los pueblos de indios se diversificó y aumentó notablemente a lo largo del siglo XVIII. Pero ¿Cuáles son los factores que explican el crecimiento económico de las cajas de comunidad? ¿En qué se gastaba el dinero de la caja comunal? ¿Qué papel desempeño la producción de los bienes de comunidad en el mercado local y regional? Son algunas interrogantes alrededor de las cuales gira este primer acercamiento.

\section{LAS REFORMAS BORBÓNICAS}

Desde mediados del siglo XVIII los borbones comenzaron a reorganizar el imperio español, a través de reformas administrativas de gobierno y una profunda transformación de la economía colonial. Hasta entonces, la Corona había cedido facultades y prerrogativas a diversos funcionarios, así como a distintas corporaciones y grupos privilegiados. ${ }^{35}$ Las reformas borbónicas tenían como finalidad, retomar aquellas facultades, jurisdicciones y beneficios que a lo largo de dos siglos había delegado a diversos miembros de la sociedad novohispana. De acuerdo con Margarita Menegus, se trataba de centralizar el gobierno y de racionalizar la economía a la luz de las ideas ilustradas. ${ }^{36}$

Tales medidas afectaron directamente a los pueblos de indios y sus empresas corporativas fueron trastocadas. Los cambios introducidos en los

33 "Relación y estado de los fondos de comunidad y reglamento de la jurisdicción de Otumba, (1794)", en Chávez Orozco (1934). En adelante se citará Chávez Orozco. 34 AGN, Indios, vol. 79, exp. 2, fs. 26-48, año de 1806.

35 Pietschmann (1992, pp. 27-65); Menegus (1988, p. 383).

36 Menegus (1999, p. 89). 
Reglamentos sobre las cajas de comunidad tuvieron dos propósitos: mejorar el aprovechamiento que hacían los pueblos de indios de sus bienes de comunidad y aumentar los ingresos monetarios.

El visitador general de Nueva España José de Gálvez se propuso optimizar la situación económica de los pueblos de indios, pues consideraba que su pobreza se debía al mal manejo que hacían de sus bienes. Con el propósito de remediar esta situación, el 30 de julio de 1765 dictó una instrucción para el arreglo de propios y arbitrios de los pueblos de indios y villas de españoles. En el inciso décimo, de dicho documento, se ordenaba la elaboración de reglamentos para el mejor gasto y organización de las cuentas de las cajas de comunidad. ${ }^{37}$

Con esta nueva reglamentación, casi se eliminó la autonomía financiera de muchas repúblicas que se sometieron a la vigilancia y las decisiones del gobierno virreinal, se redujo el gasto "superfluo" de los pueblos de indios y de las ciudades y villas de españoles. La base legal para llevar a cabo las reformas se fundamentó en la Recopilación de Leyes de 1680 y principalmente en la real Instrucción española de 1760. Por ejemplo, Francisco Antonio de Gallarreta, Contador General de Propios entre 1776 y 1784, expidió reglamentos específicos para muchos pueblos, donde se enumeraba cuales gastos quedaban suprimidos, y que cantidad se debía utilizar en las fiestas. Asimismo, se ordenaba arrendar terrenos sobrantes, presentar cuentas anuales, guardar los fondos en un arca con tres llaves, exigir a cada tributario el producto de labranza de 10 brazas de tierra comunal o contribuir con un real y medio. Como resultado de tales restricciones, los pueblos sólo podrían gastar $50 \%$ de sus caudales, y el dinero sobrante debía ser enviado a la cabecera de cada jurisdicción. ${ }^{38}$ Este cambio disminuyó la autonomía de los indios, restringió sus gastos en las fiestas religiosas, y los obligó a rendir cuentas a las autoridades españolas. Sin embargo, los pueblos no permanecieron pasivos y mostraron múltiples estrategias para continuar conservando sus bienes, por ejemplo en la Mixteca, Rodolfo Pastor detectó que el ganado de la comunidad se trasladó a poder de las cofra-

37 Menegus (1988, p. 384).

38 Tanck (1999, pp. 23-24). 
días para evitar la fiscalización de los funcionarios reales. ${ }^{39}$ En cambio, en Tlaxcala el cabildo defendió sus privilegios y se negó a dar informes de sus bienes de comunidad. ${ }^{40}$

Con la promulgación de la Real Ordenanza de Intendentes en 1786 se le otorgó a la Contaduría la facultad para integrar los Reglamentos de bienes de comunidad y para ello los subdelegados de intendentes debían recabar de los pueblos de su jurisdicción la siguiente encuesta: 1. Relación de los Propios y Arbitrios de cada pueblo. 2. Relación de las cargas perpetuas o temporales que gravaban a dichos bienes. 3. Relación de los ingresos y egresos de las comunidades señalando faltantes. 4. Relación de quien custodiaba las cuentas. Una vez recopilada la información, los intendentes, según estipulaba el artículo 33 de la misma Ordenanza, tenían la obligación de formar un reglamento interno para los propios y arbitrios o bienes de comunidad de cada pueblo, todo con el propósito de lograr una administración equilibrada de sus ingresos y egresos. ${ }^{41}$

\section{LAS CAJAS DE COMUNIDAD A PRINCIPIOS DEL SIGLO XVIII}

De acuerdo a lo estipulado por la Recopilación de Leyes de Indias de 1680, don Francisco de Salazar, alcalde mayor del partido de Otumba, mandó un informe en 1705 de los bienes de comunidad que poseían los cuatro pueblos cabecera de su jurisdicción. Antes de mencionar los bienes de cada uno, Salazar hizo una interesante síntesis de las condiciones ambientales de la zona y anotó las actividades socioeconómicas de sus habitantes:

"Y que algunos ha que por ser la tierra tan seca, tardías y escasas las lluvias o tempranos los hielos de las siembras que acostumbran de maíz, alverjón, frijol y cebada, se han perdido los frutos o la mayor parte de ellos, causa de la general pobreza de vecinos y naturales que necesitados ocurren a Haciendas de riego de otras jurisdicciones a comprar cargas de paxa que llevan en sus

39 Pastor (1987).

40 Bustamante (2010).

41 Menegus (1999, p. 91); Tanck (1999, pp. 24-26). 
burrillos todas las semanas a vender al Real de Pachuca y los que tienen bestias mulares van al obispado de Puebla a comprar maíz que tren a vender a dicho pueblo de Otumba, [...] otros se valen del fruto de los magueyes fundando ranchos de pulques que venden a los traxinantes o lo cargan más para Tetenco o México y otros se aplican al trabajo personal en las labores de vecinos por no haber más trabajo ni inteligencia en la jurisdicción". ${ }^{42}$

Como vemos, desde estos años existía una constante movilidad de los habitantes del partido de Otumba para trabajar o comercializar sus productos en otros lugares. Es probable que la misma situación se presentara en la venta e intercambio de los bienes de comunidad.

Cuatro pueblos cabeceras con sus respectivos barrios constituían la jurisdicción, a saber: San Salvador Quautlancinco, San Esteban Axapusco y Otumba llevan el agregado de la "Real Corona", en cambio San Nicolás Ostoticpac no lo lleva, quizás porque el $16.5 \%$ de sus tributarios pertenecían a Su Majestad, en tanto que el $34.5 \%$ a la encomienda de la "Condesa de Motezuma". ${ }^{43}$

En el pueblo de Otumba de la Real Corona, se habían empadronado en la última tasación tres sectores de la población; naturales, gañanes de haciendas y vecinos. Lo que indica que se trataba de un pueblo con fuertes nexos social y económico con el exterior. En 1705 se contabilizaron 152 tributarios (indios) que prestaban sus servicios a la iglesia y que además tenían bienes de comunidad; yuntas de bueyes, tierras laborías, pastos y magueyes. ${ }^{44}$ La venta de maíz y la renta de los "ranchos de pulque" generaron los principales ingresos, que fueron de 206 pesos, pero en este año se gastó la misma cantidad. A continuación se muestran los bienes de comunidad que poseían los pueblos de Otumba:

42 AGN, Indios, vol. 97, foja 326. (1705) Francisco de Salazar alcalde mayor del partido de Otumba.

43 AGN, Indios, vol. 97, foja 326v. (año 1705).

44 Un estudio detallado desde el siglo XVI sobre la cabecera de Otumba y sus pueblos sujetos que en distintos momentos dependieron y fueron transformados por las encomiendas, la real corona, la política de congregaciones y la consolidación de la república de indios y el corregimiento, puede verse en Leal y Huacuja (1984, pp. 23-27). 


\begin{tabular}{|c|c|c|c|c|}
\hline PUEBLO & TRIBUTARIOS & BIENES DE COMUNIDAD & INGRESOS & EGRESOS \\
\hline Otumba & 152 & $\begin{array}{l}\text { Yunta de bueyes, tierras } \\
\text { laborías, pastos, renta de } \\
\text { magueyes, pulque y maíz }\end{array}$ & $\$ 206.00$ & $\$ 206.00$ \\
\hline $\begin{array}{l}\text { San Nicolás } \\
\text { Ostoctipac }\end{array}$ & 51 & $\begin{array}{l}2 \text { Yunta de bueyes, } \\
16 \text { fanegas de maíz, } \\
\text { cebada, arrendamiento } \\
\text { de un terreno }\end{array}$ & 72.00 & 181.00 \\
\hline $\begin{array}{l}\text { San Salvador } \\
\text { Cuautlancinco }\end{array}$ & 34 y $1 / 2$ & $\begin{array}{l}\text { Maíz y arrendamiento } \\
\text { de un terreno }\end{array}$ & 75.00 & 90.00 \\
\hline $\begin{array}{l}\text { San Esteban } \\
\text { Axapusco }\end{array}$ & 29 & $\begin{array}{l}\text { Pastos y magueyes, } \\
\text { arrendamiento de rancho } \\
\text { de pulques, tienda } \\
\text { de venta de pulque }\end{array}$ & 216.00 & 181.00 \\
\hline
\end{tabular}

Fuente: AGN, Indios, vol. 97, fs.326-329.

Los cuatro pueblos de la jurisdicción tenían 266 1/2 tributarios y todos contaban con bienes de comunidad. Tanto el pueblo de Otumba como el de Ostoctipac tenían dos yuntas de bueyes para cultivar los terrenos comunales, además rentaban ranchos de magueyes. Cuautlancingo cultivaba una parcela de maíz. En cambio, Axapusco no tenía tierras de cultivo, pero en cambio, arrendaba dos ranchos en 36 pesos, y obtenía sus mayores ganancias de la venta de pulque, que en esta ocasión fueron de 180 pesos y el resto de rentas de ranchos.

Así, desde principios del siglo XVIII, los pueblos de la jurisdicción de Otumba obtenían sus principales ingresos de tres rubros: arrendamiento de ranchos de magueyes, venta de pulque y cultivo de maíz.

La mayor parte del dinero se utilizaba para cubrir los gastos del culto religioso: obvenciones parroquiales, misas, funciones de semana santa, corpus christi, fiestas de los santos patronos, flores, cera, adorno, cohetes y comidas. ${ }^{45}$

45 Las obvenciones parroquiales estaban constituidas por el cobro de bautizos, matrimonios y defunciones. 


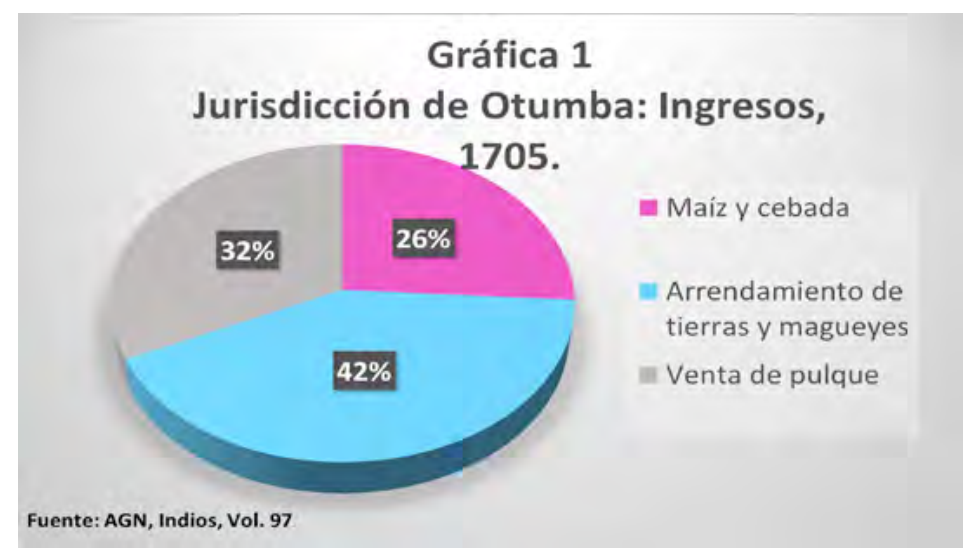

Por ejemplo, en 1705 el pueblo de Cuautlancingo tuvo un ingreso de 75 pesos, pero sus gastos fueron de 90 pesos, en cambio, Ostoctipac, obtuvo sólo 72 pesos pero gastó más del doble. En este último caso, para saldar la deuda, las autoridades de república y los vecinos dieron su cooperación. ${ }^{46}$ Llama la atención que del total de los egresos la mayor parte se dedicaba a cubrir los gastos internos y sólo una mínima parte se destinaba a las contribuciones exteriores, es decir, correo, hospital de San Lázaro y regalos al cura y al alcalde mayor.

En estos años los bienes de comunidad eran escasos y se arrendaban pocas tierras. Pero en las décadas siguientes, los pueblos de esta región ya sea por su propia iniciativa o con base en las algunas disposiciones de 1680, incrementaron el nivel de su producción, ya que para fines del siglo XVIII los pueblos de Otumba habían aumentado sus bienes y arrendaban bastantes tierras y solares. En esta dinámica de crecimiento, sin duda desempeñaron un papel fundamental, el aumento de la población y el desarrollo económico generado por las reformas borbónicas. ${ }^{47}$ En 1705, el pueblo de Otumba tenía seis barrios, a saber: "Santa Catalina”, "San Pablo", "San Juan”, “San Marcos”, "San Martín” y "Hueyapa". ${ }^{48}$ En cambio, en 1794, Otumba contaba con los pueblos y barrios

46 AGN, Indios, vol., 97, fojas 327-328.

47 Marichal (2012).

48 AGN, Indios, vol., 97, foja. 328. (1705). 
siguientes: "Pueblo Aguatepec", "Pueblo San Marcos", "Pueblo Xaltepec", "Pueblo Aztacameca", "Pueblo Tlamalapa" y "Barrio Xalmimilolpa". ${ }^{49}$ Aunque se trataba de los mismos lugares, a fines del siglo algunos ya no eran barrios sino pueblos, que probablemente contaban con su capilla y su propia república con gobernador y regidores.

Los ingresos provenientes de los bienes de comunidad no solo se ocupaban para financiar las fiestas religiosas sino también para solventar las deudas comunales, por ejemplo, en julio de 1756, el gobernador de la cabecera de Otumba manifestó que su pueblo "está padeciendo gravísima necesidades", y que no se habían pagado los "reales tributos". En este escrito se percibe el déficit y la mala planeación que padecía la caja comunal, aunque se arrendaban terrenos y los arrendatarios de los ranchos tenían adelantado dinero, la caja estaba sin fondos, "a manera que en ningún tiempo se ven libres, padeciendo la misma necesidad”. Por lo tanto, el gobernador solicitó licencia al virrey Agustín de Ahumada y Villalón, marqués de las Amarillas, para vender los ranchos de San Pablo, Santa Ana y Santa Inés, con lo cual se pretendía cubrir, "lo adeudado al ramo de reales tributos y pagar corrientes de obvenciones". La solicitud fue aceptada y días más tarde se valuaron dichos ranchos y se hicieron los pregones necesarios. ${ }^{50}$ No sabemos en qué precio ni a quienes fueron rematadas estas propiedades, pero no dudamos que se haya efectuado la venta, porque en la relación que se hizo de los bienes de comunidad en 1778 y 1794, no aparecen dichos ranchos, más bien se nombran otras propiedades, que probablemente se compraron en los años siguientes. En cambio, las finanzas de la caja de comunidad de Axapuzco eran más estables, por ejemplo, en 1737, el cabildo de indios solicitó licencia para hipotecar sus bienes de comunidad y comprar la hacienda de Nuestra Señora de la Concepción Buenavista, solicitud que no prosperó. $^{51}$

49 Chávez Orozco (1934, p. 3).

50 AGN, Indios, vol. 57, exp. 246, fojas 261-261v. (1756) "Sobre la licencia que pide para la venta de los ranchos el gobernador comisionado y los naturales de Otumba”.

51 AGN, Tierras, vol. 2350, exp. 3, f. 10. Citado en Leal y Huacuja (1984, p. 24) 
en este apartado veremos el impacto inmediato que provocó el primer intento por establecer un reglamento, cuyo fin era "mejorar" la administración de las cajas de la jurisdicción de Otumba. Para empezar, se elaboró un inventario de todas las propiedades comunales con el fin de saber sus condiciones; extensión, calidad y valor, lo que permitiría establecer remates ventajosos y arrendamientos redituables, como se aprecia en el cuadro 2.

Uno de los artículos del reglamento contemplaba que en adelante las tierras de la comunidad "se arrendaran en pública subasta para aumentar los ingresos", pues, se tenía conocimiento, que los gobernadores favorecían a ciertas personas y cobraban rentas menores. Como se percibe en el cuadro anterior el número y valor de los terrenos de cultivo y ranchos arrendados habían aumentado de manera considerable, y sumaban nueve mil pesos.

Fue así que el 20 de octubre de 1778, el alcalde mayor Joseph de León, en voz de Juan Asensio “indio ladino" y de oficio pregonero, a son de un tambor y con voz alta iniciaron los pregones para el arrendamiento de los ranchos Axoloapan, Nopaltepeque, Tlahuico, San Lorenzo, Tlalmimilolpa, San Miguel Azalco y cerro de Aguatepec, pertenecientes al común de la cabecera. Los pregones continuaron en los días siguientes hasta completar 30 como especificaba el reglamento. ${ }^{52}$

En ese contexto, el 13 de noviembre don Lorenzo de Espinosa hizo postura para que se le admitiera en las “pujas y mejoras”, ofreciendo la cantidad de 100 pesos de contado cada año por arrendamiento del rancho Tlahuico y sembrar a su costa 200 magueyes en sus linderos; 45 pesos por el de Nopaltepeque, sembrando 100 magueyes, y 35 pesos por el de San Lorenzo sembrando también 100 magueyes. Como no hubo más postores, se admitieron en arrendamiento.

En los meses siguientes se continuaron pregonando las demás tierras y ranchos, fue así como don Joseph Ortega, presentó postura por el rancho Ahuatepeque con sus magueyes y pastos, todo por la cantidad de 50 pesos cada

52 AGN, Tierras, vol. 3048, exp. 2, fs. 50-58. (año 1779). 
CUADRO 2. AVALÚO DE TERRENOS, OTUMBA 1777

\begin{tabular}{|c|c|c|}
\hline RANCHO & PROPIEDADES & VALOR \\
\hline \multirow[t]{5}{*}{ Axaloapan } & Por una caballería de magueyal de buena calidad & $1,800.00$ \\
\hline & 2 caballerías de pan llevar a 350 cada una & 700.00 \\
\hline & 1 caballería de pastos y abrevaderos con nopales & 250.00 \\
\hline & Por 2 pozos y un jaguey & 100.00 \\
\hline & Total & $2,850.00$ \\
\hline \multirow[t]{6}{*}{ Nopaltepeque } & 1 caballería de tierra de pan llevar & 400.00 \\
\hline & $\begin{array}{l}\text { Media caballería de menor } \\
\text { calidad y media inservible }\end{array}$ & 150.00 \\
\hline & 1 caballería de tierra colgada y tepetatosa & 150.00 \\
\hline & Unas matas y cercas de maguey & 100.00 \\
\hline & Por un jaguey ciego con algunas tareas de limpia & 20.00 \\
\hline & Total & 820.00 \\
\hline \multirow[t]{4}{*}{ Tlahuico } & 2 caballerías de tierra de labor 350 cada una & 700.00 \\
\hline & 2 caballerías inferior calidad 300 cada una & 600.00 \\
\hline & 2 caballerías de tierra tepetatosa, y abrevaderos & 450.00 \\
\hline & & $1,750.00$ \\
\hline $\begin{array}{l}\text { Tierras San } \\
\text { Lorenzo }\end{array}$ & 1 caballería y $3 / 4$ de labor y buena calidad & 700.00 \\
\hline $\begin{array}{l}\text { Tierras de } \\
\text { Tlalmimilolpa }\end{array}$ & 2 caballerías de a 350 cada una & 700.00 \\
\hline \multirow[t]{4}{*}{$\begin{array}{l}\text { Rancho San } \\
\text { Miguel }\end{array}$} & $\begin{array}{l}3 \text { caballería tierra de labor de } \\
\text { buena calidad } 400 \mathrm{c} / \mathrm{u}\end{array}$ & $1,200.00$ \\
\hline & Media caballería de mala calidad & 75.00 \\
\hline & Por un jaguey pequeño con agua & 50.00 \\
\hline & Total & $1,325.00$ \\
\hline \multirow{4}{*}{$\begin{array}{l}\text { Magueyal cerro } \\
\text { Aguatepeque }\end{array}$} & Media caballería de magueyal de todas calidades & 900.00 \\
\hline & Media caballería & 60.00 \\
\hline & Total & 960.00 \\
\hline & Suma total & $\$ 9,085.00$ \\
\hline
\end{tabular}

Fuente: AGN, Tierras, vol. 3048, fs. 50-53. Año I779. 
año, señalando que "estaba sumamente destruido" y prometió sembrar 100 magueyes. Postura que se admitió y el 19 de enero de 1779, no habiendo más candidatos se remató a Ortega y se elaboró un documento donde se estamparon las respectivas firmas. Llama la atención que en ese mismo mes, se presentó ante el alcalde mayor, don Matías Lorenzo Ribas, gobernador interino, los alcaldes, regidores y otros oficiales de república del mismo pueblo de Otumba, "pasados y recientes". Solicitando se suspendieran los pregones y remates del rancho Axoloapan, "por necesitarlo para su comunidad y que ellos por si entregaran en sus caxas el arrendamiento que le correspondía en cada año por el precio de su avalúo lo que afianzaran en toda forma luego que se les entregue por vía de arrendamiento". ${ }^{53}$ Es decir, querían arrendar sus propias tierras. Unos años antes esto era inusual, pues los gobernadores y su cabildo disponían de sus bienes de comunidad según sus intereses y sin pedir permiso a nadie como ahora estaba sucediendo, lo que refleja la perdida de la autonomía sobre sus recursos comunales.

En adelante, todos los arrendatarios pagaron su respectivo arrendamiento, pero cinco años más tarde, empezaron los problemas cuando el gobernador en turno don Bentura Ramírez se introdujo con “los de su facción” en tierras arrendadas, así lo denunció Francisco Espinosa en nombre de su padre que para entonces había fallecido. En su queja, apuntó que por la renta de tres ranchos estaban pagando 180 pesos anuales. Por tanto, solicitó al alcalde mayor se notificara a los indios para que se retiraran, pues el convenio era por nueve años. Además, Espinosa señaló que los tres ranchos, "antes que estos saliesen al pregón según las disposiciones dadas en dicho reglamento solo producían en cada año 75 pesos" y después que fueron arrendadas por su padre, aumentaron a 180 pesos, un incremento de más del 120 por ciento, lo que según el arrendatario "era una ventaja de que continuaran los arrendamientos en beneficio de la caja de comunidad". ${ }^{44}$ Sin embargo, pese a esta petición, Ramírez y su grupo continuaron sembrando las tierras arrendadas.

53 AGN, Tierras, vol. 3048, exp. 2, fs. 65-66. (año 1779).

54 AGN, Tierras, 3048, exp. 2, fs. 71-73. (año 1784). 
El alcalde mayor notificó a Ramírez en varias ocasiones y como éste no acató la orden de abandonar los terrenos invadidos fue acusado "de insubordinación e inobediencia” y luego encarcelado en Otumba en mayo de 1784. Para su desgracia, unos días después se presentó el nuevo gobernador Andrés Francisco López con sus regidores, alguaciles y "demás común”, denunciando a Bentura Ramírez, por haberse quedado con 300 pesos cuando había sido gobernador cuatro años antes "que fue cuando lo quitamos a los seis meses por revoltoso", y ahora solicitaban se hiciera una revisión de las cuentas que había presentado Ramírez en el año anterior.

En respuesta, Ramírez y algunos que lo apoyaban enviaron una carta al protector de indios, señalando que había recibido golpes cuando se le hizo prisionero y que los terrenos arrendados que ya tenían ellos sembrados habían sido invadidos por el ganado de Espinosa "dejándonos sin esperanza de levantar las cosechas de maíz”, además de pedir su libertad señaló que el "actual gobernador tenía una íntima amistad con el alcalde mayor y lo querían perjudicar”, por tanto, solicitaba su libertad bajo fianza para presentar nuevamente sus cuentas. Sin embargo, el fiscal protector de indios resolvió que los motivos por los que se encontraba Ramírez en la cárcel eran justos y dictaminó "no haber lugar a la soltura que pretende hasta satisfacer las cuentas pendientes" y turnó el expediente a la Contaduría de Propios y Arbitrios.

Hasta entonces se revisaron las cuentas del exgobernador Bentura Ramírez, el resultado revela un enorme desfalco a la caja de comunidad del pueblo de Otumba, y también coadyuva a explicar el interés de las élites por tratar de recuperar el control de la república pues les dejaba ganancias. En su cuenta del año 1783, Ramírez había anotado ingresos por un monto de 369 pesos, en cambio, los egresos daban un total de 624 pesos, es decir había un adeudo de 255 pesos. Sin embargo, cuando la república y la Contaduría hicieron la revisión exhaustiva sobre todos los ranchos y tierras arrendadas, así como venta de maíz, cebada y zacate, el monto de los ingresos sumó la cantidad de 1,200 pesos un real y seis granos, y según "los resultados que ha sacado esta Contaduría y la republica de Otumba deben quedar a favor de la comunidad y reintegrar el gobernador los novecientos cincuenta y cinco pesos seis granos". Cuando esto sucedía, corría el mes de noviembre de 1784, y se habían 
embargado los bienes del exgobernador, los que se pondrían en pública subasta, pero después de varios meses en prisión Bentura Ramírez estaba enfermo de fiebre, dolores reumáticos e hidropesía, causado en parte por la humedad de la cárcel y falta de alimentos. ${ }^{55}$

El desfalco de la caja comunal nos remite a varias consideraciones. En primer lugar, se percibe una lucha entre las élites locales por el manejo y administración de los bienes de comunidad, que como vimos en este caso ocultaba actos de autoritarismo y corrupción. Probablemente, si no hubiera sido por el establecimiento de un reglamento, la vigilancia de la Contaduría y la denuncia de un grupo desplazado, difícilmente hubieran quedado evidencias de la corrupción y los intereses que tenían las élites locales sobre los recursos comunitarios. Al mismo tiempo, se percibe que los pueblos de indios estaban perdiendo autonomía y sus líderes las prerrogativas y beneficios que les redituaba el manejo de los bienes de comunidad en una comunidad cada vez menos homogénea y a veces dividida.

\section{LA SITUACIÓN AL FINAL DEL SIGLO XVIII}

Antes de las reformas, los excedentes de la caja de comunidad estaban en manos del pueblo de indios, y eran utilizados en beneficio del común y como vimos, de las élites locales. La política borbónica empezó a restringir las funciones que cumplía la caja de comunidad, la más importante fue la eliminación de la contabilidad de la mayor parte que gravaba a los pueblos de indios, es decir los tributos reales. A partir de entonces el dinero de las cajas de comunidad, desde la óptica ilustrada, se encauzaría a solventar actividades útiles, como el salario del maestro de escuela, que resultó ser una nueva carga. (Tanck, 1994)

Otro de los objetivos perseguidos por la Junta Superior de Propios y Arbitrios era arrendar al mejor postor las tierras sobrantes de la comunidad, y al aplicarse tales medidas, en el caso de los pueblos de Otumba los ingresos por arrendamientos se incrementaron más del $50 \%$. No obstante, para fines del siglo XVIII, pese las reformas borbónicas y la mayor injerencia de las

55 AGN, Tierras, Vol. 3048, exp. 2, fs. 114-119. (año 1784). 
autoridades coloniales, una parte considerable de las tierras de esta zona todavía estaban bajo el dominio de los pueblos de indios. Por ejemplo, en la cabecera de Otumba, las tierras de comunidad eran trabajadas en común y la cosecha se vendía en el mercado, pero también otra porción de tierras conocidas como propios, fueron arrendadas no solo a rancheros y hacendados españoles, sino también a la élite indígena. ${ }^{56}$ Sin embargo, también hay que decir, que desde el siglo XVII y a lo largo del siglo XVIII se fue consolidando un proceso de concentración de la propiedad en manos españolas y criollas, por ejemplo en 1717 existían 17 personas que eran dueñas de 13 ranchos y 10 haciendas en la Jurisdicción de Otumba. ${ }^{57}$

El común de Otumba también arrendaba solares con su respectiva casa, probablemente a españoles y mestizos que se habían avecindado en el pueblo. En 1794, arrendó 38 solares, obteniendo anualmente por este concepto 66 pesos cuatro reales. ${ }^{58}$ Incluso las tierras rentadas para la producción de pulque, tenían pequeños jacales (quizás construidos por los arrendatarios), algunos contaban con corrales y pequeños "xagueyes". Es probable que esta situación, con el tiempo provocara que los arrendatarios se sintieran con derechos de propiedad sobre los sitios que habían arrendado y donde habían invertido un capital. ${ }^{59} \mathrm{Si}$ bien la transferencia formal de las tierras corporativas a individuos sucedió formalmente hasta mediados del siglo XIX con el proceso de desamortización, detectamos que desde fines del siglo XVIII se estaba gestando el futuro traspaso de tierras de comunidad a rancheros españoles y a la par propició el desarrollo de ranchos y haciendas en la región de Otumba.

Thomas Charlton hizo un estudio detallado sobre la tenencia de la tierra a fines del siglo XVIII y calcula la producción de maíz por hectárea en la jurisdicción de Otumba. Para este investigador, las tierras más fértiles para el cultivo de maíz estaban en manos de la comunidad y eran usufructuadas por las familias indias y la élite local. En cambio, las tierras menos productivas, fueron

56 Charlton (1991, p. 236).

57 Leal y Huacuja (1984, pp. 27-28).

58 Chávez Orozco (1934: 9-17).

59 Charlton (1991, p. 249). 
rentadas a extraños para la producción de pulque. ${ }^{60}$ En 1794 la caja de comunidad del pueblo de Otumba contaba con 546 pesos cuatro reales, que había obtenido de:

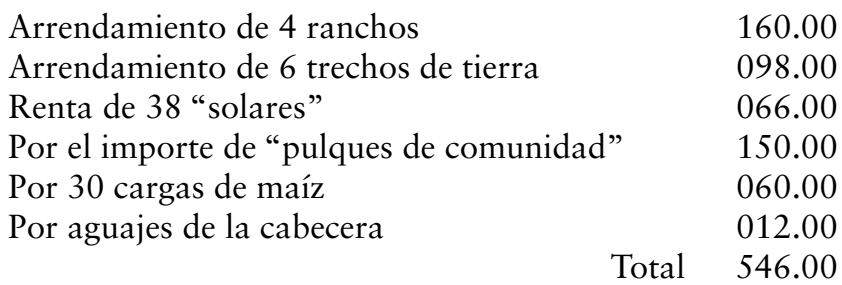

Como vemos los principales ingresos de la cabecera de Otumba provenían del arrendamiento de tierras y solares; $60 \%$, el resto de otros ramos como venta de pulque y maíz, según se aprecia en la siguiente gráfica:

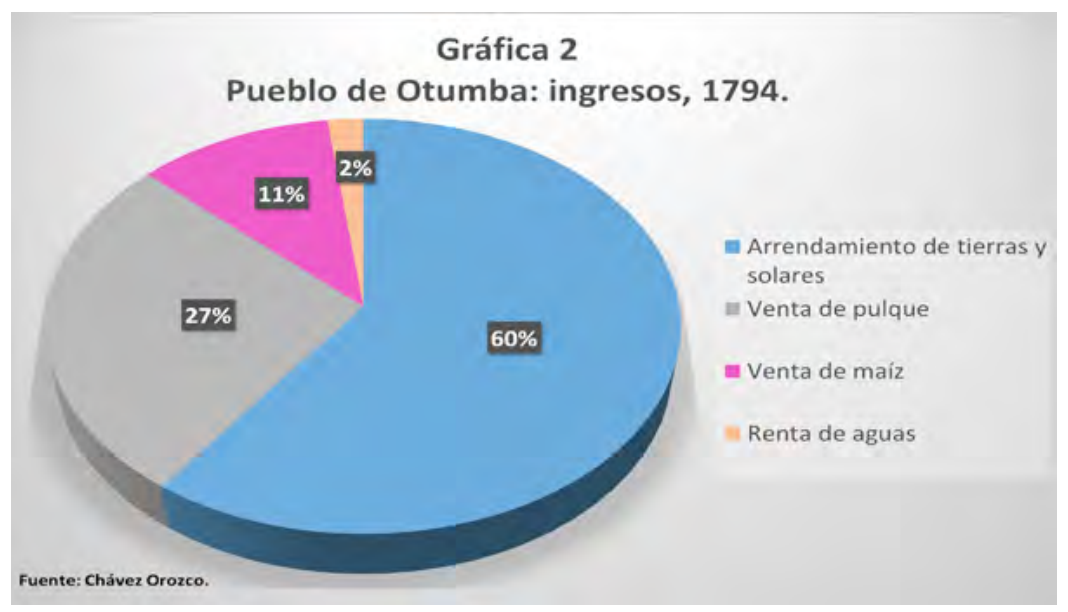

En cambio, en este mismo año los gastos sumaron la cantidad de 532 pesos, cinco reales y 10 granos, de los cuales 356 pesos se habían gastado para pagar los derechos parroquiales de las diversas fiestas de los santos; 127 pesos con cuatro reales fueron para el salario del maestro, y lo restante para cubrir

60 Charlton (1991, p. 244). 
otros gastos. En este año, se prohibieron algunos gastos como la contribución al Hospital de San Lázaro, regalías al subdelegado, correo y recorte de los gastos en las festividades religiosas.

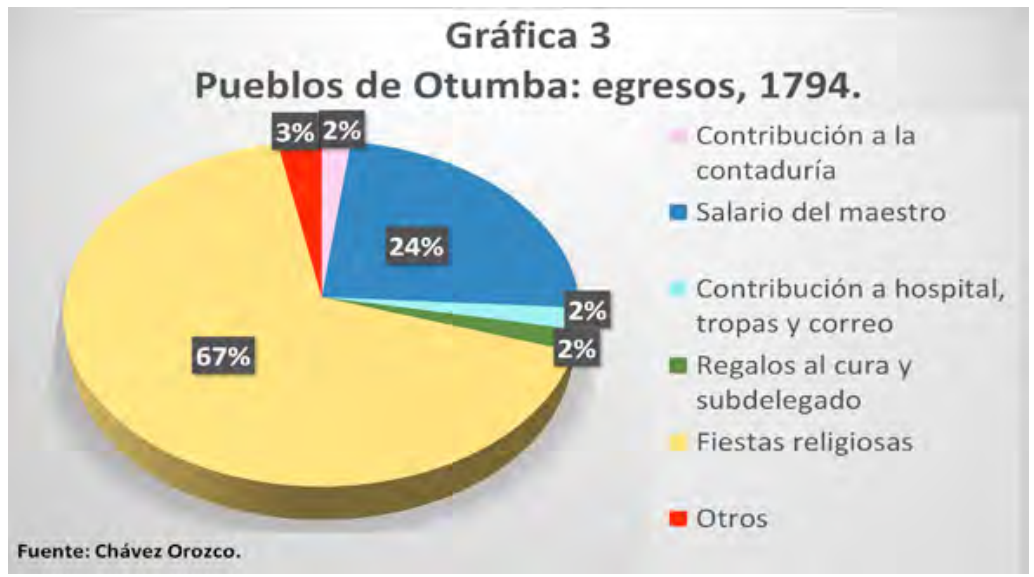

Sólo en la semana mayor o semana santa se gastaron 121 pesos cinco reales y seis granos, en tanto que en la fiesta patronal de nuestra Señora de la Concepción se erogaron 111 pesos y cinco reales. Otras fiestas fueron; tres de mayo (siete pesos un real), Espíritu Santo (13 pesos dos reales), Corpus Christi (40 pesos tres reales), Señora de Guadalupe (15 pesos).

Todavía en 1794, los cuatro pueblos de la subdelegación de Otumba utilizaban la mayor parte de sus ingresos para financiar los gastos de las funciones religiosas. En otras palabras, los pueblos continuaron manteniendo cierto control de sus recursos y los destinaron a las fiestas de los santos a pesar de que esto iba en contra de los Reglamentos. La siguiente gráfica que incluye a los cuatro pueblos de Otumba es elocuente al respecto: 


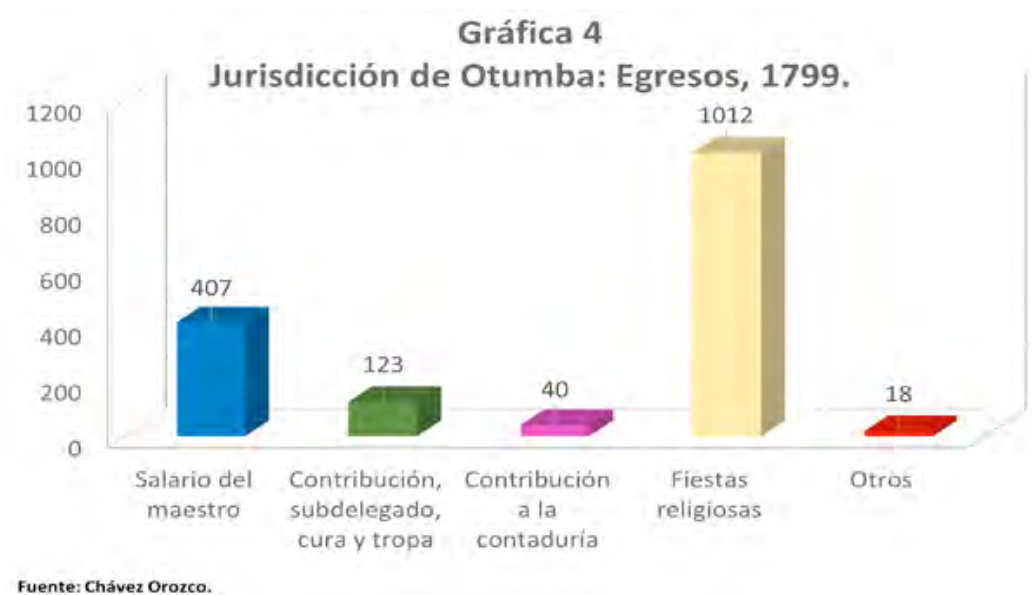

Con estos datos, no resulta extraño que Chávez Orozco señalara que la iglesia fuera la responsable directa de la miseria del indio, según sus palabras, "durante el época colonial, el régimen eclesiástico contribuyó a detener al indio en su evolución social y fue un obstáculo para el desarrollo económico y espiritual del indígena". Asimismo, manifestó que fue la iglesia y no el imperio español quien se apropió de la mayor parte de los ingresos generados por las cajas de comunidad. ${ }^{61}$ Sin embargo, Chávez Orozco no distinguió los cambios que generó la aplicación de la Ordenanza de Intendentes sobre los bienes y cajas de comunidad, tampoco sobre los reglamentos que se establecieron en muchos pueblos, y que propiciaron que una parte de los excedentes se orientara a las arcas reales.

La fiscalización de los bienes y cajas de comunidad por el gobierno provocó malestar entre los indios, pues no sólo significaba la rigurosa recaudación de un impuesto, el real y medio, en adición al tributo, sino además, marginaba a los gobernantes indios de las ganancias que representaba la administración de las cosechas comunales, del arrendamiento de tierras y del manejo del dinero. ${ }^{62}$ Los respectivos reglamentos obligaron a los pueblos a entregar al gobierno

61 Chávez Orozco (1934, p, 3).

62 Tanck (1999, p. 495). 
más de la mitad de su ingreso anual, con la supuesta promesa de que se les devolvería para ayuda en tiempos de hambre o epidemia. Sin embargo, se instaló un proceso complicado y largo para obtener la devolución del sobrante para las necesidades del pueblo, parte del cual había sido enviado al Banco de San Carlos y a la compañía de Filipinas. Por ejemplo, entre 1793 y 1794 el gobierno reunió en donativos y préstamos casi 500.000 pesos de los bienes de comunidad para financiar la guerra con Francia, y entre 1795 y 1799, para ayudar en el conflicto contra Inglaterra, nuevamente sacó casi 500.000 pesos, para llegar a un total de cerca de un millón de pesos. ${ }^{63}$ Dinero que nunca volvió a manos de los pueblos de indios.

\section{INDICIOS DEL COMERCIO REGIONAL}

El crecimiento sostenido de la producción de plata a lo largo del siglo XVIII determinó una reorganización de la agricultura y la ganadería para satisfacer la demanda de diversos productos en las minas y ciudades, ${ }^{64}$ asimismo, el aumento de la población provocó la apertura de nuevas tierras de cultivo, más que de innovaciones tecnológicas. En el norte se incorporaron tierras baldías, algo similar sucedió en el centro donde los rancheros y hacendados añadieron tierras incultas mediante el arrendamiento, como se percibe en los pueblos de Otumba y en otras regiones de la Nueva España que también vivieron cambios importantes estimulados por el crecimiento económico del norte y por la política de exportación de materias primas impulsadas por la corona. ${ }^{65}$ Por si fuera poco, el descubrimiento de minas, fundación de nuevos poblados norteños y la creación de otros Consulados de comerciantes generó el crecimiento económico de ciudades como Guadalajara y Veracruz, vinculando a nuevas regiones a través del intercambio y compra venta de diversos productos, como ganado, cereales y textiles. ${ }^{66}$ Los comerciantes indígenas también participaron

63 Tanck (1999, p. 496); Lamas (1957).

64 Coatsworth (1990); Marichal (2012); Ibarra (2000).

65 Van Young (1989). Menegus y Tortolero (1999, pp. 13-16); Marichal (2012).

66 Ibarra (2000); Van Young (1989). 
activamente en estas transacciones a través del repartimiento de mercancías y la venta de sus productos colectivos de cofradías y bienes de comunidad. ${ }^{67}$ Hay indicios que manifiestan que los habitantes de Otumba, vendieron sus productos en las minas de Pachuca, Real del Monte, y en las ciudades de Texcoco, México y Puebla. Según Leal y Huacuja, fue hasta la segunda mitad del siglo XVIII cuando el cultivo de magueyes y la producción de pulque sentaron las bases de la economía en la zona de Otumba y generaron la expansión pulquera de varias haciendas como San Antonio Xala y Ometusco. ${ }^{68}$

La región central (México, Valle de Cuernavaca, Puebla y Tlaxcala) tuvieron también algunos cambios en el uso y explotación de sus tierras. Muy cerca de Otumba, en las haciendas pulqueras de los llanos de Apan, hubo un crecimiento de este sector lo que supuso un cambio importante. Tradicionalmente la producción de pulque era una actividad restringida a los indios, pero la aparición de las haciendas pulqueras fomentó que fueran éstas las que abastecieran a los centros urbanos de la bebida tradicional en detrimento de la producción indígena. Este sector fue afectado por las reformas introducidas en el ramo, así como por los impuestos que los gravaban. Al igual que otros ramos de la Real Hacienda, la corona se hizo cargo de su administración cesando los arrendamientos en 1761. Los impuestos sobre el ramo del pulque eran de tres tipos: por el plantío de magueyes, por su entrada y venta en las ciudades, con lo que afectaban la producción indígena y su consumo a nivel doméstico. En 1780 aumentó el impuesto por entrada y venta, de un real a real y medio, y de medio real que se pagaba en el pulque tlachique a un real por arroba. ${ }^{69}$

Pese a todo, a fines del siglo XVIII, los cuatro pueblos de la subdelegación de Otumba mantuvieron su producción de magueyes y pulque que los vinculó al mercado regional, no sólo arrendaban sus tierras comunales para la producción de pulque a rancheros mestizos y españoles, sino también vendían el pulque por su cuenta. Entre los bienes del pueblo de Otumba se encontraban seis mil

67 Castro (2010, pp.92-101); Garavaglia y Grosso (1987); Silva (1004); Hamnett (1976);

Ouweneel (2000); Arrioja (2011); Baskes (1996); Machuca (2012).

68 Leal y Huacuja (1984, p. 32).

69 Menegus y Tortolero (1999, p. 116-117). 
magueyes, que le generaron 150 pesos al año. El pueblo de Axapuzco tenía 20 mil magueyes de comunidad y por cuya venta de pulque obtuvo la suma de 770 pesos en un año. ¿Hacía donde iba esta producción? Creemos que al igual que la producción de pulque de las hacienda que se transportaba a Texcoco, Pachuca y la ciudad de México ${ }^{70}$ también, los pueblos las desplazaban a esos mismos destinos y vendían la bebida localmente, por ejemplo, el pueblo de Axapuzco era dueño de un expendio de pulques en el centro de Otumba. ${ }^{71}$

La siguiente gráfica muestra que después del arrendamiento de ranchos y solares, la renta de magueyes y la venta de pulque generaban casi el $40 \%$ de los ingresos:

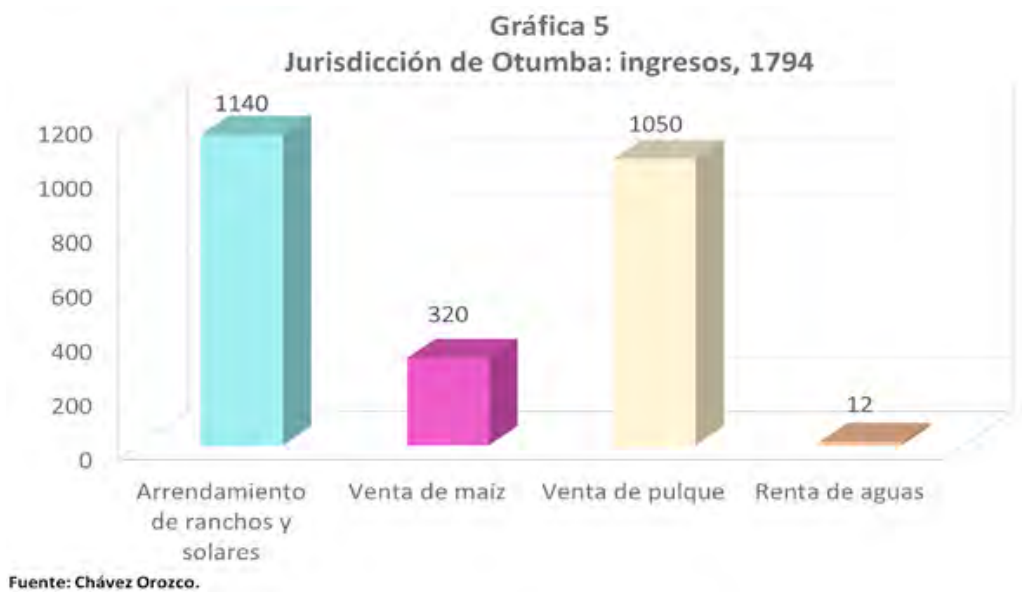

La región de Otumba se ubica en una situación privilegiada y seguramente la mayor parte de sus productos los vendía en la cercana ciudad de México, aunque todavía no detectamos quienes eran los que comerciaban los productos comunales, todo indica que eran las autoridades de república los que efectuaban las transacciones.

70 Leal y Huacuja (1984, pp. 43-45).

71 Citado en Chávez Orozco (1934, 1934, p, 85). (1794) "Relación y estado de las cajas de comunidad de la cabecera de Otumba”. 
En el centro de México, los pueblos de indios mantuvieron una clara vinculación con la tierra y una fuerte tradición de comerciar con sus excedentes. Si bien algunos pueblos fueron perdiendo sus tierras o parte de ellas durante el siglo XVIII la mayoría conservó un territorio relativamente suficiente. Es probable que Otumba al igual que el valle de Toluca, durante este periodo, estableciera una relación simbiótica y compleja entre los pueblos de indios, el pequeño comercio, las haciendas y ciudades cercanas. Según Menegus, a pesar del desarrollo de la hacienda española, los indios comerciantes o no abastecían poco mas de la mitad de la villa de Toluca. Entre los productos comercializados sobresalían; frijol, cebada, cerdos, manteca, miel, leña, carbón, frazadas, etc. ${ }^{72}$ En el caso de Otumba, los indios estaban integrados a la economía regional, por medio de su trabajo y la compra venta de diferentes artículos. Por ejemplo, en la semana santa de 1794, con el dinero proveniente de la caja de comunidad se compraron artículos externos, a saber; adornos, ocho docenas de palma, una carga de plátanos, una carga de naranjas, vasos para los candiles, incienso, pólvora, y "una y media gruesa de cohetes". Asimismo, en la fiesta patronal de Otumba, se compró chocolate, cera, “aceite para la lámpara” y se gastaron 46 pesos en los "fuegos pirotécnicos". ${ }^{73}$ Esto refleja que existía un fuerte intercambio comercial con otros pueblos y principalmente con la ciudad de México, donde se expendían todo tipo de productos textiles, agrícolas y ganaderos. ${ }^{74}$

$\mathrm{Al}$ igual que el valle de Toluca y Puebla, los pueblos de Otumba no estaban aislados ni se redujeron al autoconsumo, por el contrario, vendían sus productos agrícolas y artesanales, todo con el propósito de procurarse dinero para solventar el pago de tributos, las obvenciones y celebrar sus fiestas.

\section{EL ARRENDAMIENTO DE TIERRAS COMUNALES}

Una de las políticas implementadas para sanear la economía de la caja de comunidad fue dar en arrendamiento las tierras sobrantes. Los reglamentos su-

72 Menegus (1995, p. 140).

73 Chávez Orozco (1934, pp. 20-32).

74 Marichal (2012, p. 100). 
gerían que habían de preferirse como arrendadores en primer término a los miembros del propio pueblo. ${ }^{75}$ Cuestión que no siempre se respetó, porque se dio preferencia al mejor postor.

Los cuatro pueblos que conformaban la subdelegación de Otumba en 1795, arrendaban tierras comunales (ranchos, tierras laborías y solares), por ejemplo, el pueblo de Otumba arrendaba tres ranchos con su respectiva casa y xaguey (160,00 pesos); seis tierras laborías (95.00); y 38 solares ubicados en la cabecera (65 pesos tres reales).

En lo que se refiere a los cambios introducidos por el nuevo reglamento de Otumba, los ranchos y tierras laborías, continuarían arrendándose, pero con la condición que se rematasen al mejor postor, por el término de cinco años y con las formalidades y prescripciones de los artículos 31 y 44 de la Real Ordenanza de Intendentes. En tanto que los arrendamientos de los solares "no se innovarán ni alterarán en manera alguna por ser justos y equitativos". ${ }^{76}$

El reglamento especificaba que a través de la caja de comunidad se continuaría administrando las magueyeras y pulques, y se seguiría cultivando las dos "bezanas de tierra y manejando los xagueyes". Asimismo, se eliminaron, los tres pesos que la caja contribuía anualmente a favor del Hospital de San Lázaro en la ciudad de México y la contribución al correo. Por otro lado, se prohibió la costumbre de gastar 12 pesos cuatro reales para la festividad de "La purificación de nuestra señora", y también para dar regalos del dinero de la caja al subdelegado y al sacerdote, pues "no hay necesidad que los bienes de comunidad soporten tales gastos". ${ }^{77}$

Al igual que Otumba, San Esteban Axapuzco aumentó sus bienes de comunidad y la renta de sus tierras a lo largo del siglo XVIII, si en 1705 sólo contaba con pocos bienes, para 1794, su caja de comunidad era la más rica de los cuatro pueblos:

goza esta comunidad cuatro pertenencias de tierra que distingue con las nominaciones de Rancho de San Marcos Papalote, el Nuevo, San Mateo

75 Menegus (1989, p. 386).

76 Chávez Orozco (pp. 13-16).

77 Chávez Orozco (pp. 20-25). 
y Tecpactepec, y no obstante que en sus términos son dilatados carecen de cascos y demás formalidades de tales ranchos, pues aunque se advierten varias reducidas fábricas de viviendas, ni estas son propias de los indios como ya se expresará, ni tampoco se hallan ubicadas con distinción o de manera que dividan las pertenencias, y a esta causa no se sientan con particularidad sus circunstancias y dimensiones, parte de los suelos o su mitad podrá estar destinada a la labor y la otra se compone de nopaleras, arboledas y también magueyales. Son varios los arrendatarios de estas tierras y sus trechos y respectivos arriendos son los siguientes. ${ }^{78}$

He aquí las 23 tierras y ranchos arrendados en 1794 que generaban la cantidad 516 pesos cuatro reales:

\begin{tabular}{|c|c|c|c|c|}
\hline RaNCHO & $\begin{array}{c}\text { TIPO DE } \\
\text { TIERRA }\end{array}$ & CAPACIDAD & ARRENDATARIO & RENTA ANUAL \\
\hline $\begin{array}{l}\text { Llano } \\
\text { Papalote }\end{array}$ & Laborías & 8 fanegas maíz & Pedro Villegas & $\$ 40.00$ \\
\hline “ & “ & $31 / 2$ & José de León & 30.00 \\
\hline “ & “ & 9 & Miguel Montaño & 100.00 \\
\hline “ & “ & 6 & José Miguel Montaño & 30.00 \\
\hline “ & “ & 1 & Matías Hernández & 16.00 \\
\hline “ & “ & 6 & Felipe Hernández & 60.00 \\
\hline “ & “ & $61 / 2$ & Guillermo Carrillo & 50.00 \\
\hline “ & “ & 4 & Roque González & 33.00 \\
\hline “ & “ & $4 \frac{1}{2}$ & José González Perlín & 30.00 \\
\hline San Marcos & “ & $1 / 2$ & Vicente Mendoza & 3.00 \\
\hline San Mateo & “ & 3 & Manuel de Luna & 27.00 \\
\hline $\begin{array}{l}\text { Rancho } \\
\text { Nuevo }\end{array}$ & Pastos & - & Paulina Ruiz & 6.00 \\
\hline
\end{tabular}

78 Chávez Orozco, p. 78. 


\begin{tabular}{|c|c|c|c|c|}
\hline RANCHO & $\begin{array}{l}\text { TIPO DE } \\
\text { TIERRA }\end{array}$ & CAPACIDAD & ARRENDATARIO & RENTA ANUAL \\
\hline “ & “ & - & Francisco Ruiz & 3.00 \\
\hline “ & “ & - & Victoriano de Islas & 4.00 \\
\hline “ & “ & - & Antonio Badillo & 8.00 \\
\hline Tecopatepec & Pastos & - & Bernarda Lizalde & 6.00 \\
\hline “ & “ & - & José Vázquez & 12.00 \\
\hline “ & “ & - & Francisco Rodríguez & 4.00 \\
\hline “ & $\begin{array}{l}\text { Pastos y } \\
\text { laborías }\end{array}$ & 1 & Ana Josefa Vázquez & 15.00 \\
\hline “ & “ & $11 / 2$ & Antonio Vázquez & 11.00 \\
\hline “ & Pastos & - & Fernando Roldán & 6.00 \\
\hline “ & $\begin{array}{l}\text { Pastos y } \\
\text { laborías }\end{array}$ & 6 cuartillos & Antonio Álvarez & 3.00 \\
\hline \multirow[t]{2}{*}{ “ } & Laborías & $1 / 2$ & Miguel Téllez & 2.00 \\
\hline & & & & 516.4 reales \\
\hline
\end{tabular}

Fuente: Chávez Orzoco (1934, pp. 78-82).

Las reformas reforzaron la economía india, ya que la imposición del pago de real y medio para cubrir los tributos y gastos de la comunidad, así como el arrendamiento de las tierras sobrantes y la venta de sus productos sirvieron para aumentar el ingreso monetario de las cajas de comunidad en las últimas décadas del siglo de las luces. Sin embargo, este panorama de crecimiento empezó a tambalearse en el umbral del siglo siguiente, como consecuencia de la crisis y los préstamos forzosos exigidos por la corona a distintos sectores novohispanos para sostener sus guerras trasatlánticas. ${ }^{79}$ En 1806 , pese a que la caja de comunidad de la cabecera de Otumba tuvo un ingreso de 602 pesos por la renta de siete ranchos, 42 solares y venta de pulque ${ }^{80}$ resulta interesante

79 Marichal (2012, p. 113).

80 AGN, Indios, vol. 79, exp. 2, fs, 26-48. (año 1806). 
contrastarla con las cuentas de dos décadas antes cuando sus ingresos totales eran de más de 1,000 pesos, y todavía en 1794, por la renta de 38 solares habían cobrado 66 pesos, en cambio, para 1806 se pretendía obtener 72 pesos por 42 solares, lo que indica que los precios se mantuvieron casi igual para los inquilinos pequeños que iban en aumento, en cambio, la renta de los ranchos disminuyó de manera notable, quizá porque a partir de 1804 la "Consolidación de vales reales" afectó el sistema crediticio de los comerciantes, mineros, rancheros y hacendados, descapitalizando la economía novohispana desde antes de $1810 .^{81}$

En otras palabras, los pueblos de la jurisdicción de Otumba, pese a los primeros reglamentos que se intentaron establecer en 1776 y luego en 1794, éstos no se aplicaron al pie de la letra y los gobernadores lograron evadir su total cumplimiento y con ciertas restricciones continuaron manejando los bienes de comunidad y ocuparon una parte considerable de los ingresos para financiar el culto religioso como indican las cifras de las gráficas 3 y 4 . Por ejemplo, en 1794 la cabecera de Otumba gastó el $67 \%$ en sus fiestas y $24 \%$ para pagar al maestro de escuela. Pero si consideramos los egresos de los cuatro pueblos en ese año, 1,012 pesos se ocuparon en fiestas, 407 para cubrir el salario del maestro de escuela, 123 para pagar contribuciones a la Contaduría, al cura y subdelegado, 18 pesos para hospital, tropa y otros gastos.

Al mismo tiempo, se entabló una lucha entre la burocracia virreinal, los curas y las élites locales por el control y el manejo de los bienes de comunidad, y a la par surgieron numerosos conflictos y acusaciones por la malversación de los fondos de las cajas comunales. Quizá con el fin de solucionar los problemas, y de encauzar en definitiva los sobrantes a las cajas reales, entre 1803 y 1806 se elaboró otro reglamento más detallado que contenía 18 artículos encaminados a poner candados más rígidos y desmantelar el poder de los pueblos de Otumba. ${ }^{82}$ Aparte de disminuir el gasto en las fiestas, prohibir gratificaciones y el uso de "fuegos pirotécnicos", cobrar el dos por ciento sobre la producción total, promover el arrendamiento de tierras al mejor postor,

81 Marichal $(2012,99)$.

82 AGN, Indios, vol. 79, exp. 2, fs, 26-48. (año de 1806). 
prohibir el pago de salarios de autoridades locales y subdelegados de las cajas de comunidad, y ejercer una estricta vigilancia de las autoridades locales, los ingresos y el dinero sobrante se guardaría en una arca con tres llaves y quedaría depositados bajo la responsabilidad del subdelegado. Con tales políticas las autoridades locales perdieron el derecho a disponer de ellos, quedando esa disposición en manos del intendente y la Junta Superior de Hacienda. ${ }^{83}$

Incluso, se elaboró un reglamento concreto para cada uno de los pueblos de Otumba, que para entonces sumaban seis, pues se incluyeron dos nuevos pueblos cabecera; Santo Domingo Estameca y San Miguel Xaltepec. Por ejemplo, el reglamento de Axapuzco, apuntó que el ingreso anual de la caja de comunidad era de 1,500.50 pesos, de los cuales solo se gastarían 180 pesos para el salario del maestro, 30 pesos por el $2 \%$ para la Tesorería, 184 para cuatro fiestas y 11 pesos para el Hospital de San Lázaro y gastos menores, quedando un sobrante de 1,095.50 pesos que pasaría a la Contaduría para su supuesto resguardo. ${ }^{84}$ Lo mismo sucedió en la cabecera de Otumba, allí de un total de 602 pesos, 325 pesos quedaron como sobrante y solo se autorizó un gasto de 276 pesos, de los cuales se gastarían 110 pesos para la fiesta titular, corpus christi y semana santa, es decir, hubo una reducción considerable, si en 1794 se había gastado el $67 \%$ en fiestas ahora solo se les permitió gastar aproximadamente el $20 \% .{ }^{85}$ Sin embargo, esta extracción del dinero sobrante de las cajas de comunidad duraría pocos años, los grupos bélicos que pasaron por esta zona se apropiaron de los recursos comunales y paralizaron los arrendamientos y la producción durante las guerras de independencia. ${ }^{86}$

En suma, los reglamentos de 1806 que se elaboraron para los pueblos de la jurisdicción de Otumba disminuyeron la autonomía de los pueblos y encauzaron el dinero sobrante hacía las arcas reales. Cuando los gobernantes indios fueron desplazados de la administración casi autónoma de los recursos comunales, probablemente perdieron el interés sobre el ahorro comunitario.

83 Menegus (1988, pp. 777-778).

84 AGN, Indios, Vol. 79, exp. 2, fs. 26-28.

85 AGN, Indios, vol. 79, exp. 2, fs. 46-47.

86 Nava (1971, pp. 355-357). 
En cambio, los curas intentaron seguir obteniendo las ganancias que les generaba el culto católico, pero las circunstancias eran diferentes, ahora el dinero sobrante estaba en poder de las arcas reales y no podía ser utilizado para todas las fiestas ni comidas como en el pasado. A partir de entonces las autoridades de los pueblos darían cuenta de sus acciones, verificarían los arrendamientos ante el subdelegado y limitarían sus gastos religiosos. Aunque no por mucho tiempo, la guerra de independencia y la fundación de la república mexicana, dejaría por otras décadas los bienes de comunidad en manos de los gobiernos locales del Estado de México. ${ }^{87}$

\section{CONCLUSIÓN}

Los bienes de comunidad fueron el principal sustento económico del régimen comunal de los pueblos de indios de la jurisdicción de Otumba y de otras regiones de la Nueva España. Esta empresa colectiva administrada por la república permitió mantener la cohesión y organización interna para producir colectivamente, vender los recursos y obtener ingresos para solventar la administración, construir templos, emprender obras públicas, financiar las fiestas, comprar ornamentos religiosos y completar el tributo. Pero al mismo tiempo, se han esclarecido algunas razones que motivaron la participación activa de las élites locales de los pueblos de indios, quienes se disputaron el control de los bienes y la administración de la caja comunal porque les redituaba poder y beneficios personales, como se observó en el caso de algunos gobernadores de Otumba a fines del siglo XVIII.

Como hemos visto, la tendencia para controlar los bienes de los pueblos por parte del gobierno español provenía desde fines del siglo XVII pero esta política se fortaleció con las reformas borbónicas y el establecimiento de la Contaduría de Propios Arbitrios y Bienes de Comunidad. De modo que con la aplicación de reglamentos específicos para cada pueblo, hacia fines del siglo XVIII (aunque no para todos) se empezó a marginar a los gobernantes locales de la administración de la caja comunal. Así de acuerdo con otros autores, la

87 Birrichaga (2003). 
autonomía que habían gozado los pueblos de indios y sus autoridades locales disminuyó paulatinamente. ${ }^{88}$ Sin embargo, los pueblos no permanecieron pasivos y no solo evadieron y simularon los reglamentos, sino incluso entablaron pleitos legales e ilegales contra pueblos rivales, propietarios particulares, funcionarios públicos y sacerdotes, y al mismo tiempo mostraron múltiples estrategias para conservar sus bienes de comunidad y parte de sus costumbres religiosas, como sucedió en los pueblos de Otumba, que a pesar de los reglamentos establecidos en 1778 y 1794, trataron de pasarlos por alto y continuar gastando la mayor parte del dinero en sus fiestas religiosas, así que para remediar esta situación se elaboró otro reglamento en 1806 que puso candados a estas prácticas disminuyendo la autonomía y el control de los bienes de comunidad por parte de los pueblos y autoridades locales. En otras palabras, el estudio incluyó dos niveles de análisis, desde arriba, consideró la política de la corona a través de la legislación y los reglamentos, desde abajo, la respuesta de los actores sociales involucrados.

Finalmente, aunque la subdelegación de Otumba, no fue de gran riqueza y población, quedó claro que tuvo un crecimiento económico importante y un movimiento más dinámico a fines del siglo XVIII como lo reflejan sus bienes y cuentas de la caja de comunidad que aumentaron de manera notable. Sin embargo, el análisis de la producción de estos bienes y las cajas de comunidad de los cuatro pueblos de Otumba, ha sido insuficiente para establecer una imagen completa de su economía y su relación con el mercado regional. En el futuro, será necesario acudir a otras fuentes complementarias como las cofradías, el tributo y la alcabala durante este periodo, para esclarecer con datos estadísticos el crecimiento económico regional como sucedió en regiones vecinas como Tepeaca, Puebla. ${ }^{89}$ Pese a estas limitantes, no se debe minimizar la producción colectiva de los pueblos de indios, pues sin duda desempeñaron un papel importante en la economía regional que sólo ha sido tratado parcialmente por la historiografía mexicana.

88 Menegus (1988); Terán (2003); Cedeño (2003) Marín (2013).

89 Pieschmann (1988); Groso (1999); Garavaglia y Groso (1987). 


\section{ARCHIVOS}

- AGN: Archivo General de la Nación, México

\section{BIBLIOGRAFÍA}

- Arrioja, D. L. (2011). Pueblos de indios, tierras y economía. Villa Alta Oaxaca: 1742-1856. Zamora. Michoacán: El Colegio de Michoacán: Fideicomiso Felipe Teixidor y Monserrat.

- Baskes, J. (1996). Coerced or Voluntary? The repartimiento and Market Participation of Peasants in Late Colonial Oaxaca, Journal of Latin American Studies 28 (parte 1), 1-28.

- Bechtloff, D. (1996). Las cofradías en Michoacán durante la época colonial. Zamora. Michoacán: El Colegio de Michoacán/El Colegio Mexiquense.

- Birrichaga, G. D. (2003). Administración de tierras y bienes comunales. Política, organización territorial y comunidad de los pueblos de Texcoco, 1812-1857, Tesis de doctorado de Historia, El Colegio de México.

- Bustamante, C. (2010). Los propios y bienes de comunidad en la provincia de Tlaxcala durante la aplicación de las Reformas Borbónicas, 1787-1804. Estudios de Historia Novohispana 43, 145-182.

- Castro, F. (2010). La sociedad indígena colonial. En S. Kuntz (coord.). Historia económica general de México. De la colonia a nuestros días (pp. 83-112). México: El Colegio de México/Secretaría de Economía.

- Carmagnani, M. (1988). El regreso de los dioses: el proceso de reconstitución de la identidad étnica en Oaxaca, siglos XVII y XVIII. México: Fondo de Cultura Económica.

- Carrera, E., J. Cruz, Z.J. Pérez y C. Cruz. (Coords.). (2011). Las voces de la fe. Las cofradias en México (Siglos XVII-XIX). México: CIESAS/UAM.

- Caso, A., S. Zavala, et al. (1954). Métodos y resultados de la política indigenista en México. V. VI. México: Instituto Nacional Indigenista.

- Cedeño, P. G. (2003). Finanzas y cajas de comunidad en los pueblos indígenas de Michoacán (1692-1775). En C. Paredes y M. Terán. (Coords.). Autoridad y Gobierno indígena en Michoacán. V. 1 (pp. 267-284). México: El Colegio de Michoacán/CIESAS/INAH/Universidad Michoacana de San Nicolás de Hidalgo. 
- Céspedes, G., (1996), Las cecas indianas en 1536-1825. Las casas de moneda en los reinos de Indias. V. 1. Madrid: Museo de la Casa de Moneda.

- Coatsworth, J. (1990). Los orígenes del atraso: nueve ensayos de historia económica en los siglos XVIII y XIX. México: Alianza.

- Cruz, P. C. (2011). Los bienes de los santos: cofradías y hermandades de la Huasteca en la época colonial. México: CIESAS/El Colegio de San Luis.

- Charlton, T. (1991). Land Tenure and Agricultural Production in the Otumba Region, 1785-1803. En H. R. Harvey (comp.). Land and Politics in the Valley of Mexico. A two Thousand year perspective. Alburquerque: University of New Mexico.

- Chávez Orozco, L. (Ed.). (1934). Las cajas de comunidades indígenas de la Nueva España. México: Secretaría de Economía Nacional.

- Dehouve, D. (1988). El pueblo de indios y el mercado: Tlapa en el siglo XVIII. En A. Ouweneel, C. Torales Pacheco. (Comps.). Empresarios, Indios y Estado. Perfil de la economía mexicana (siglo XVIII) (pp. 86-102). México: Universidad Iberoamericana, Departamento de Historia.

- Dehouve, D, (2001). Cuando los banqueros eran santos. Historia económica y social de la provincia de Tlapa Guerrero. México: Universidad Autónoma de Guerrero/ Centro Francés de Estudios Mexicanos y Centroamericanos.

- Escobar, A. (2000). El comercio en las huastecas. Los indígenas y su participación. En J. Silva, y A. Escobar. (Coords.). Mercados indígenas en México, Chile y Argentina, siglos XVIII y XIX (pp. 87-115). México: Instituto de Investigaciones Dr. José María Luis Mora/CIESAS.

- Escobar, A., V. Gayol, D. Navarrete. (2012). Indígenas y comercio en la Nueva España del siglo XVIII (Ixmiquilpan, Guadalajara, Huasteca Potosina, Tehuantepec, Tulancingo, Tlaxcala). México: Universidad Autónoma del Estado de Hidalgo.

- Fagoga, R. (2004). Circuitos mercantiles de la huasteca potosina, 1743-1812. Tesis de maestría en Historia, México: El Colegio de San Luis Potosí.

- Hamnett, B. (1976). Política y comercio en el sur de México, 1750-1821. México: Instituto Mexicano del Comercio Exterior de México.

- Garavaglia, J.C. y J.C. Grosso. (1987). El abasto de una villa novohispana: mercancías y flujos mercantiles en Tepeaca (1780-1820). Anuario IEHS 2, 217-253. 
- García, M. B. (2005). Los pueblos de la sierra. El poder y el espacio entre los indios del norte de puebla hasta 1700. México: El Colegio de México. Primera reimpresión.

- Grosso, J. C. (1999). Campesinos, poblados de hacienda y producción indígena: Tepeaca a fines del siglo XVIII. En M. Menegus. (Comp.). Dos décadas de investigación en historia económica comparada en América Latina (pp. 223-248). México: El Colegio de México/CIESAS/Instituto Mora/UNAM.

- Ibarra, A. (2000). La organización regional del mercado interno novohispano. La economía colonial de Guadalajara, 1770-1804. México: UNAM/BUAP.

- Lamas, A. (1957). Las cajas de comunidad. Trimestre Económico 24 (25), 300-307.

- Lara, T. (2005). Historia de una caja de comunidad. Tehuacán 1586-1630. México: CNCA, INAH.

- Lavrin, A. (1988). Cofradías novohispanas, economía moral y espiritual. En M. P. Martínez, G. Von Wobeser y J. Muñoz (Coords.). Cofradías, capellanías y obras pías en América colonial (pp. 49-64). México: UNAM.

- Leal, J. F. y M. Huacuja. (1984). Economía y sistema de haciendas en México. La hacienda pulquera en el cambio. Siglos XVIII, XIX y XX. México: Editorial Era.

- Lira, A. (1980). La voz comunidad en la Recopilación de 1680. Relaciones. Estudios de historia y sociedad 18, 74-92.

- Lira, A. (1995). Comunidades indígenas frente a la ciudad de México. Tenochtitlán y Tlatelolco, sus pueblos y barrios, 1812-1919. México: El Colegio de México. Segunda edición.

- Machuca, L. (2012). La participación indígena en el mercado: prácticas comerciales y circuitos mercantiles en el Istmo de Tehuantepec durante el siglo XVIII. En A. Escobar, V. Gayol et al. Indígenas y comercio en la Nueva España del siglo XVIII, (Ixmiquilpan, Guadalajara, Huasteca Potosina, Tehuantepec, Tulancingo, Tlaxcala) (pp. 49-76). México: Universidad Autónoma del Estado de Hidalgo.

- Marichal, C. (2012). La economía mexicana. De la época borbónica al México independiente, 1760-1855. En A. Kuntz (Coord.). La economía mexicana, 15192010 (pp. 80-147). México: El Colegio de México. 
- Marín, T. M. (2013). La república de indios de nuestra señora de la Asunción Parácuaro, 1787-1810. En G. López, C. Velasco y M. Aguilar. (Coords.). Etnohistoria del ámbito posmisional en México (pp. 237-265). México: INAH.

- Martínez, M. P., G. Von Wobeser y J. Muñoz (Coords.). Cofradías, capellanías y obras pías en América colonial. México: UNAM.

- Mendoza, G. E. (2002). El ganado comunal en la Mixteca Alta de la época colonial al siglo XX. El caso de Tepelmeme. Historia Mexicana LI (4), 749-785.

- Mendoza, G. E. (2004). Los bienes de comunidad y la defensa de las tierras en la Mixteca Oaxaqueña. Cohesión y autonomía de Santo Domingo Tepenene. México: Senado de la República.

- Mendoza, G. E. (2011). Municipios, cofradías y tierras comunales. Los pueblos chocholtecos de Oaxaca en el siglo XIX. México: CIESAS/UABJO/UAM.

- Menegus Bonermann, M. (1988). Las reformas borbónicas en las comunidades de indios (Comentarios al reglamento de Bienes de Comunidad de Metepec). En B. Bernal. (Comp.). Memoria del IV Congreso de Historia del Derecho Mexicano (1986). T. 1 (pp. 755-791). México: UNAM.

- Menegus Bonermann, M. (1989). Los bienes de comunidad y las reformas borbónicas (1786-1814). En Estructuras agrarias y reformismo ilustrado en la España del siglo XVIII (pp. 383-389). España: Ministerio de Agricultura y Alimentación.

- Menegus Bonermann, M. (1995). La participación indígena en los mercados del valle de Toluca. En Mercados y circuitos mercantiles en Latinoamérica. Siglo XVIII y XIX. México: Instituto Mora/UNAM.

- Menegus Bonermann, M. (1999). Los bienes de comunidad de los pueblos de indios a fines del periodo colonial. En M. Menegus Bonermann, A. Tortolero. (Eds.). Agricultura Mexicana: crecimiento e innovaciones. México: Instituto Mora/COLMICH/COLMEX/ UNAM.

- Menegus Bonermann, M. y A. Tortolero. (1999). El paisaje agrario: regiones y producción en el siglo XVIII. Introducción. En Menegus Bonermann, M. y A. Tortolero. (Eds.). Agricultura mexicana: crecimiento e innovaciones. México: Instituto Mora/COLMICH/COLMEX/UNAM.

- Nava Oteo, G. (1971). Caja de bienes de comunidades indígenas. Anales del Museo Nacional de México 2, 349-359. 
- Navarrete, D. (2012). El comercio indígena en Tulancingo a fines del siglo XVIII: mercancías, actores y espacios económicos. En A. Escobar, V. Gayol et al. Indígenas y comercio en la Nueva España del siglo XVIII, (Ixmiquilpan, Guadalajara, Huasteca Potosina, Tehuantepec, Tulancingo, Tlaxcala) (pp. 77-100. México: Universidad Autónoma del Estado de Hidalgo.

- Ortelli, H. (2011). La participación indígena en los mercados iberoamericanos. De la colonia a los primeros años independientes. Debates, Nuevo Mundo, Mundos nuevos $\mathrm{http} / /$ nuevomundo.revues.org/60764.

- Ouweneel, A. (2000). El gobernador de indios, el repartimiento de comercios y la caja de comunidad en los pueblos de indios del México central (siglo XVIII). En M. Menegus Bonermann. (Coord.). El repartimiento forzoso de mercancías en México, Perú y Filipinas (pp. 65-97). México: Instituto Mora/UNAM.

- Ouweneel, A. y C. Torales. (Comps.). (1988). Empresarios, Indios y Estado. Perfil de la economía mexicana (siglo XVIII). México: Universidad Iberoamericana, Departamento de Historia.

- Palomo, I. (2009). Juntos y congregados. Historia de las cofradías en los pueblos de indios tzotziles y tzeltales de Chiapas. (Siglos XVI al XIX). México: CIESAS.

- Pieschmann, H. (1988). Agricultura rural indígena en el México de la segunda mitad del siglo XVIII", en Ouweneel, A. y C. Torales. (Comps.). (1988). Empresarios, Indios y Estado. Perfil de la economía mexicana (siglo XVIII) (pp. 71-85). México: Universidad Iberoamericana, Departamento de Historia.

- Pietchmann, H. (1992). Protoliberalismo, reformas borbónicas y revolución: la Nueva España en el último tercio del siglo XVIII. En J. Vásquez. (Comp.). Interpretaciones del siglo XVIII mexicano. El impacto de las reformas borbónicas (pp. 27-65). México: Nueva Imagen.

- Pastor, R. (1987). Campesino y reformas. La Mixteca, 1750-1856. México: El Colegio de México.

- Ramírez, V. (2012). El comercio en las jurisdicciones de Ixmiquilpan, Actopan y Tetepango-Hueypuchtla, siglos XVIII-XIX. En A. Escobar, V. Gayol et al. Indígenas y comercio en la Nueva España del siglo XVIII, (Ixmiquilpan, Guadalajara, Huasteca Potosina, Tehuantepec, Tulancingo, Tlaxcala) (pp. 101-142). México: Universidad Autónoma del Estado de Hidalgo. 
- Randall, R. (1977). Real del Monte: una empresa minera británica en México. México: Fondo de Cultura Económica.

- Romano, R., (1998). Moneda, seudomonedas y circulación monetarias en la economía de México. México: El Colegio de México/Fondo de Cultura Económica/ Fideicomiso Historia de las Américas.

- Silva, J. (1994). La participación indígena en el abasto de la villa de Zamora 1792. Secuencia 29.

- Silva, R. y A. Escobar. (Coords.). (2000). Mercados indígenas en México, Chile y Argentina, siglos XVIII y XIX. México: Instituto Mora/CIESAS.

- Solís, G. (2003). Tierra y trabajo en las haciendas de cofradías indígenas de Yucatán, siglo XVIII. Desacatos 13, 13-31.

- Tanck, D. (1994). Escuelas y cajas de comunidad en Yucatán al final de la colonia. Historia Mexicana XLIII (3), 401-449.

- Tanck, D. (1999). Pueblos de indios y educación en el México colonial, 1750-1821. México: El Colegio de México.

- Terán, M. (2003). El liderazgo indio de Valladolid. La diversidad de gobiernos en los pueblos y la política indigenista borbónica. En C. Paredes y M. Terán. (Coords.). Autoridad y Gobierno indígena en Michoacán. V. 1 (pp. 361-368). México: El Colegio de Michoacán/ CIESAS/INAH/Universidad Michoacana de San Nicolás de Hidalgo.

- Van Young, E. (1989). La ciudad y el campo en el México del siglo XVIII: La economía rural de la región de Guadalajara, 1675-1820. México: Fondo de Cultura Económica.

- Wolf, E. (1957). Closed Corporate Peasant Communities in Mesoamerica and Central Java. Southwestern Journal of Anthropology 13 (1). 